\title{
THE OBSTACLES TO ENERGY SAVING IN RESIDENTIAL BUILDINGS IN NIGERIA: STAKEHOLDERS' PERSPECTIVES
}

\author{
Aisha Tilde Ibrahim ${ }^{1}$ and Nirodha Gayani Fernando ${ }^{2}$
}

\begin{abstract}
Over the past three decades research on energy use in buildings has become significant due to increasing scientific and political pressure on issues concerning global warming and climate change. As part of the impact by climate change, tropical nations are faced with several challenges in achieving energy savings, particularly the energy consumption behaviour of building occupants, with very little research coming from Africa. Previous research has shown that variations due to occupant behaviour is substantial. To address these challenges in line with the objectives of some of the UN Sustainable Development Goals (SDGs) (namely, clean and sustainable energy, as well as climate action) in residential buildings, this paper explores the perceptions of stakeholders by identifying the barriers which affect energy use from different cultural perspectives. Qualitative data were collected using semi-structured telephone interviews with experts in the energy and construction fields in Nigeria. The purpose of the interviews was to provide an insight into residential energy consumption behaviour and the barriers faced in the adoption of sustainable energy sources. The results were analysed using an energy cultural framework. An analysis of the results shows that continuous awareness of energy saving behavioural change, government subsidies for renewable energy, government checks, and the standardization of energy-efficient appliances imported into the country can improve people's trust regarding sustainable choices and can promote efficient energy use. The outcome from this work is expected to give a better understanding of energy use behaviour and inform future energy policies and interventions related to household energy saving.
\end{abstract}

Keywords: Barriers; Energy saving; Energy culture framework; Stakeholders.

\section{INTRODUCTION}

Energy is essential for sustained human development, social improvement and economic growth. Moreover, sufficient energy at an affordable price is a necessity for economic stability and is also regarded as vital for the sustainable development of a nation (Sepúlveda, 2016a). The literature has shown that the building industry is viewed as a major contributor to energy consumption and greenhouse gas emissions (Allouhi et al., 2015) and the International Energy Agency has advised on the relevance of effective measures to be put in place to mitigate the effect of climate change in the energy sector (International Energy Agency, 2015). In Europe, about a third of total energy use and

\footnotetext{
${ }^{1}$ School of Science, Engineering and Environment, University of Salford, United Kingdom, a.i.tilde@edu.salford.ac.uk

${ }^{2}$ School of Science, Engineering and Environment, University of Salford, United Kingdom, n.g.fernando1@salford.ac.uk
} 
carbon emissions is as a result of household energy use (Dietz et al., 2009; Bertoldi, 2012) and this has the possibility of being reduced by up to $20 \%$ in a decade with the implementation of non-regulatory interventions (Dietz et al., 2009). As a result, there are suggestions that accomplishing the reduction of these carbon emissions through interventions that consider social, cultural, psychological and organizational factors can influence our choice of energy which could be beneficial (Stern et al., 2016). While technical advances and tougher environmental regulations are important requisites for improving energy efficiency (Geels et al., 2018), several researchers argue that behavioural factors demand more attention (Sovacool, 2014). Therefore, solving energy challenges also requires improvements in human behaviour and in successfully shifting consumer behaviour in the desired direction. As previously emphasized in literature, energy is used by people/occupants and not buildings (Janda, 2011). To adopt a more sustainable practice to complement innovative solutions for energy efficiency, the behaviour, as well as attitude, of occupants are crucial. Therefore, the main research question of this study is "What are the challenges to the adoption of energy saving practices in Nigerian residential buildings?". Accordingly, this study attempts to identify the challenges to making energy savings in residential buildings by contacting experts in the energy and building sectors. The purpose of the main research (upon which this paper is based) is to develop a model for the reduction of energy consumption within residential buildings in Nigeria from an end use perspective to inform understanding. The paper is structured to discuss the present state of energy (electrical energy) consumption in Nigeria and then presents the methodology adopted for the study. This will be followed by a discussion on the challenges faced by stakeholders in the energy and construction sector with analysis and discussions in this regard.

\section{LITERATURE SYNTHESIS}

\subsection{BACKGROUND TO THE STUDY}

Residential buildings' net energy demands can be reduced through technical and behavioural interventions (Ornaghi et al., 2018). Technical interventions can be implemented at the design or operational stages of a building. However, behavioural changes aim to improve the environmental consciousness of occupants. There is a vital need for the efficient management of energy and for investigations into the inherent challenges or barriers to energy saving within residential buildings. In analysing efficient energy management in buildings, Pelenur and colleagues attributed demographics as key barriers to energy efficiency measure adoption in the UK residential sector (Pelenur and Cruickshank, 2012). Stieß and colleagues also analysed homeowners who used low and zero carbon technologies as compared to those who carried out standard refurbishment measures (Stieß et al., 2013). The work also allows homeowners to assess achieving their objectives in residential refurbishments and the associated barriers. The study observed that a major barrier to achieving energy-efficient refurbishment measures is poor dissemination of information and transfer of knowledge.

Further studies examined data from a 2009 survey of more than 400 owner-occupiers of single-family detached and semi-detached houses to identify key drivers for, and barriers to, the adoption of building energy retrofits in Germany (Achtnicht et al., 2014). It was noted that private owners with financial capacity are likely to carry out building retrofit to achieve efficient energy savings. Furthermore, a survey of technology adopters has 
been carried out by Caird et al. (2008) to investigate the drivers for, and barriers to, the adoption of energy efficiency measures and renewable energy systems. Price barriers were identified as one of the reasons for rejecting technologies (Caird et al., 2008). It was noted that when considering the input of stakeholders, Caird et al. (2008) looked at the perceptions of the stakeholders involved in the building life cycle and industrial value change were sorted to identify barriers of significance to the industry. The greatest challenge identified in this was the inefficiency in terms of how energy savings, translated into benefits and profits. This resulted in the identification of three major barriers which were dissatisfaction with policy design and implementation, stakeholder lack of implementation capacity for developing and constructing high-performance new residential buildings, as well as an inadequate legalization of the relevant market ( $\mathrm{Li}$ et al., 2019). Furthermore, studies by Camarasa et al. (2021) by interviewing a range of stakeholders in European Union countries, identified technical and economic barriers as the main barriers to the adoption of energy efficient technologies (Camarasa et al., 2021). This, amongst other research, underscores the crucial need to consider studies on energy savings' behaviour with a focus on barriers and on stakeholders' perspective. It is also noted that most of the literature that was analysed for this study with focus on barriers are studies conducted in Europe and Asia. Hence, similar studies in African countries, particularly Nigeria, will be a valuable addition to the research database in this area.

\subsection{Current Status OF The POWER Industry IN Nigeria}

Nigeria is one of the largest oil producing nations in the world with a population of over 190 million people (Olaniyan et al., 2018). It is a lower medium-income economy with a per capita income of about $\$ 2,250$ (World Bank, 2019). Undeveloped electricity production systems exist in the country making the generation and distribution of electricity unreliable (Urban et al., 2007; Emodi and Yusuf, 2015). Currently, Nigeria is the largest nation in Africa. It accounts for almost half of West Africa's total population and more than 15 per cent of the entire African continent's total population (World Bank, 2019). Nigeria is the largest oil producer in Africa, with around 37 billion barrels of proven oil reserves and 203.16 trillion cubic feet of established natural gas reserves (EIA), 2020). This has enabled fuel energy to be available at a lower cost (through government subsidies) in comparison to international prices. The generated electricity in the country consists of a combination of three hydro and nine thermal power generation plants, with thermal generation based on gas (Remy et al., 2021). The generation plants have a total installed capacity of $6910 \mathrm{MW}$ generated mainly from hydro power and fossil fuel (oil and natural gas) with a ratio of $27.9 \%$ and $67.2 \%$ respectively (AFDB, 2011; National Energy Policy (NEP), 2003). Nigeria's grid supplies underperform as compared to other developing countries (Adeniyi, 2019). This is because more than half of the electricity generated is estimated to be off the grid, mostly by diesel and gasoline generators. In 2018 the Nigerian government estimated that Nigeria needed to install at least $40 \mathrm{GW}$ (Gigawatts) by 2020 to meet its then projected goal to become one of the 20 largest economies in the world by 2020 (Ikpe and Torriti, 2018). Unfortunately, that target was not achieved and currently it is not a realistic target as a result of numerous challenges associated with the power sector. These challenges, amongst other factors, are the main focus of this paper, that is, to determine the obstacles to energy savings within Nigeria residential building is the main focus area by considering the aggregate views of key stakeholders in this regard. 


\section{METHODOLOGY}

The chosen data collection method for the study was the interview. This is because it encourages researchers to explore the beliefs, motivations, views and experiences of the subjects concerning the investigated phenomenon (King et al., 2018). Additionally, the semi-structured interview format was chosen as it offers the opportunity for the interviewer to ask additional questions or follow-up questions and to change the questions based on the interviewees' answers (thus seeking more detailed answers). This study is part of a larger sequential exploratory mixed-method research where interviews are carried out first, and the data obtained are expected to inform the quantitative aspect of the study (Saunders et al., 2019) As a result of the Covid pandemic and subsequent lockdowns, telephone interviews were considered to be most appropriate method to undertake the interviews. Although researchers generally disapprove of telephone interviews, often citing the lack of visual cues, establishing a rapport and interaction (Gillham, 2005; Hargreaves et al., 2013; Burton, 2018), they are inexpensive, convenient and easily generate a substantial amount of data (Babin et al., 2019).

To get an in-depth insight into the barriers to energy efficiency, an interview schedule was created. The interviewees consisted of ten professionals from the Nigerian electricity and construction industry. The reason for the interviews was to obtain independent viewpoints from a cross-section of stakeholders to generate qualitative data as an initial pilot study. A similar approach has been employed for exploring an area when there is a scarcity of empirical data in the specific area of research (Trotta, 2018). Purposive sampling was used to identify the energy and construction experts (energy providers, energy regulators, energy consultants and construction contractors) who were consulted for the qualitative interviews. Additionally, the stakeholders were selected on accessibility and from the contacts that the researcher had with the Nigerian electricity and construction industry? However, before the interviews were conducted, preliminary contacts were undertaken through an introductory phone call, an email to explain the research and why their participation would be appreciated, and to set up an interview. The participants had 5-15 years' experience in the energy and construction industry. All participants were recruited voluntarily and signed a consent form which pre-informed them of their voluntary participation and the nature of the study. All the participants except for participant $\mathrm{G}$ had experience of working in the electricity industry. The consultant (participant $\mathrm{G}$ ) had various experiences of dealing with key electricity providers around Nigeria, which positioned him as an appropriate participant for this research. The telephone interviews were recorded, transcribed and analysed. The analysis processes involved coding and constructing themes by classifying similarities in the interview data, with thematic analysis used to analyse the results.

\section{RESULTS AND DISCUSSION}

\subsection{ANALYSIS OF DATA}

The analysis started with the transcription of the interviews. This involved listening to the recorded audio, transcribing, and clarifying in-depth with the participants, which was followed by the generation of coding and themes. The data analysis used here depended on the research question and the research design. This technique is effective in understanding patterns across the data about the respondents' experiences, practices and behaviour (Braun et al., 2016). This method was performed using Microsoft Excel and 
thematic analysis was used (Braun and Clarke, 2006). Since the transcriptions of the interview were based on semi-structured questions, some of the responses were difficult to categorise as they were lengthy and subject to the experience, opinions and perceptions of the interviewees. For this purpose, the researcher concentrated mainly on the research questions (and in this case is, "what are the barriers to energy saving in Nigeria from a stakeholder perspective?") while not ignoring the valuable additional knowledge that emerged from the interview sessions. To safeguard the confidentiality of the results, the participants involved were labelled alphabetically.

\subsubsection{The Factors that Could Influence Energy Efficiency Implementation}

There were several factors, identified by the participants, that are important in enhancing or militating against energy efficiency behaviour. These include a lack of leadership commitment to energy efficiency; poor incentives; mixed messages sent out by providers on the value of efficiency offers and a lack of clarity in policy direction on energyefficient savings. Other factors are a lack of cross-government buy-in to efficient energy use; a lack of enforcement of mandatory standards, a lack of helpful information, training and accountability, as well as ignorance of the term sustainability, thus it is having little impact. Some of these factors will be discussed in more detail subsequently.

\subsubsection{Lack of Leadership Commitment Towards Energy Efficiency}

The lack of leadership commitment has been identified as one of the major barriers towards achieving energy efficiency in Nigerian residential buildings. According to participant A as shown in Table 1, most Chief Executives of both government and private organisations responsible for the coordination or implementation of energy policies either lack the understanding of energy efficiency or are complacent on the approach required to effectively drive the implementation of policies, programmes and directives in this regard. This assertion is also supported by the literature, namely that leadership commitment is lacking in attaining the efficient utilisation of energy (Hart et al., 2009). It was noted that a lack of active participation by the leadership of organisations in the energy sector has a negative impact on energy efficiency in households. Table 1 also shows that over $70 \%$ of the responses are in agreement that a lack of leadership is a shortcoming with the statistical trend showing similar views.

This lack of leadership from the executives reflects on performance within the industry and exhibits a lack of accountability for energy efficiency. Without a leader's commitment to energy efficiency, those making sourcing decisions will be unclear on what priority to give to efficiency, and also will be left in doubt about how to deliver efficiency in energy savings. It is pertinent to note the attitude of the leadership within an organization generally reflects in the behaviour of their subordinates (such as in services' delivery and in efficient energy savings for residential buildings in Nigeria). Participants noted that: The result of this lack of leadership is that commitment in principle to sustainable development and energy efficiency did not translate into sustainability in practice.

\subsubsection{Lack of Reliable Information and Training}

Participants D and F concurred that it is important to look at the role information and training play in achieving energy efficiency. Regarding this barrier, over 60 per cent of the participants substantiated that a lack of reliable information affects sustainable energy saving behaviour. Such a lack of sufficient information can be manifested in households not using energy saving equipment. Generally, there is poor understanding of the benefits 
of energy saving. A comprehensive initiative by the Government to address the barriers expatiated by Participants $\mathrm{F}$ and $\mathrm{G}$ will deliver a clear and consistent signal to the market for sustainable technologies. It will ensure that the sector values sustainability in enhancing the chances of achieving UN SDG. It will also help the sector to ratchet up supplier and product performance over time and to identify potential savings. It will put Nigeria among the leaders in sustainable development. Existing training courses are often traditional or generic in nature and do not focus on how to deliver sustainable energy. This is because the training providers are not sustainability specialists. There is a lack of experienced practitioners to deliver sustainability training to staff.

Table 1: Obstacles to energy efficiency and sustainable development implementation

\begin{tabular}{|c|c|c|c|c|c|c|c|}
\hline $\begin{array}{c}\text { Barriers/ } \\
\text { motivative factors }\end{array}$ & $\begin{array}{c}\text { Participant } \\
\text { A }\end{array}$ & $\begin{array}{l}\text { Participant } \\
\text { B }\end{array}$ & $\underset{\text { C }}{\text { Participant }}$ & $\begin{array}{c}\text { Participant } \\
\text { D }\end{array}$ & $\begin{array}{l}\text { Participant } \\
\text { E }\end{array}$ & $\begin{array}{l}\text { Participant } \\
\text { F }\end{array}$ & $\begin{array}{l}\text { Participant } \\
\text { G }\end{array}$ \\
\hline $\begin{array}{l}\text { Lack of } \\
\text { leadership } \\
\text { commitment }\end{array}$ & $\sqrt{ }$ & $\sqrt{ }$ & $\sqrt{ }$ & & $\sqrt{ }$ & & $\sqrt{ }$ \\
\hline $\begin{array}{l}\text { Lack of helpful } \\
\text { information and } \\
\text { training }\end{array}$ & & $\sqrt{ }$ & & $\sqrt{ }$ & & $\sqrt{ }$ & $\sqrt{ }$ \\
\hline $\begin{array}{l}\text { Inadequate use of } \\
\text { new technologies }\end{array}$ & $\sqrt{ }$ & & & & $\sqrt{ }$ & $\sqrt{ }$ & \\
\hline $\begin{array}{l}\text { Poor financial } \\
\text { support }\end{array}$ & & $\sqrt{ }$ & & & & $\sqrt{ }$ & \\
\hline $\begin{array}{l}\text { Social and } \\
\text { organisational } \\
\text { challenges }\end{array}$ & & & $\sqrt{ }$ & $\sqrt{ }$ & & & $\sqrt{ }$ \\
\hline
\end{tabular}

\subsubsection{Inadequate Use of Technologies}

Lack of integration of new technology is considered as a barrier to efficient energy saving practice in Nigerian residential Sector. Because Nigeria is not a technology advanced country, most of the new technologies for sustainable energy are imported from different countries. As a result, proliferations of such technologies are experienced with limited capacity for standardization. It was further noted the use of these technologies amongst residences, with some of the available technologies with compatibilities issues and difficult to integrate. All these are serious barriers to achieving sustainable efficient energy savings amongst residential sector in Nigeria as highlighted by Participants A, E and $\mathrm{F}$ in Table 1.

"You know Nigeria is a developing market, and this comes with non-availability of technology, inadequate technologies, poor quality of designs, poor codes and standards associated with technology, poor performance of green buildings, lack of proven alternate energy-efficient technologies, lack of labelling and measurement standards; these are some of the barriers identified which are associated with incompatible technology." [Participant A].

"For progress in energy efficiency, new and innovative and renewable materials need to be developed which may replace new and conventional materials. Lack of success of new 
and greener materials, non-availability of green and energy-efficient materials are some of the barriers which are an important part of technological barriers." [Participant F].

\subsubsection{Poor Financial Support}

The challenge to achieving energy efficiency and, broadly, sustainability is accelerated among the smaller service providers because of financial constraints. A willingness to provide financial support to providers could help to boost their energy efficiency. This was noted when analysing the contributions of some participants.

According to Participant B, "a lack of financial means is an important factor impeding the energy efficiency programmes of service providers in Nigeria."

"...well some of the problems we are facing are lack of efficient funds, lack of capital for energy efficiency projects, lack of access to capital for carrying out energy efficiency projects, limited availability of resources and inappropriate infrastructural support; these are some of the factors contributing to the scarcity of financial means" [Part F].

\section{DISCUSSIONS}

One of the major barriers to the implementation of sustainable and efficient energy practice in residential buildings in Nigeria is the lack of leadership commitment from both government and private sector organisations. It is shown in Table 1 that more than $70 \%$ of respondents are of the view that leadership commitment to driving policies and programmes on sustainable energy efficiency is extremely low. This is contrary to the current commitment of the Nigerian Government in achieving sustainable development goals. UN Sustainable Development Goals. Judging from responses from Participants A and G, an unclear direction and coordination strategy on energy saving from the leadership of most organisations indicates that efforts of individual staff override any organisational drive to facilitate an energy efficiency process. This sentiment is also shared by Participants $\mathrm{B}$ and $\mathrm{C}$, as analysed above, where they reiterated that the implementation of energy efficiency in most organisations in Nigeria is left for individuals rather than being driven from the Chief Executives, without a clear direction for the organisations on implementation of energy policies. Additionally, this factor also showcases the slow pace of implementing the UN SDGs by Nigeria. In the same vein, Participant E stated that there is a lack of incentives to promote and encourage energy efficiency amongst communities or dwellings and this is a barrier to achieving energy efficiency in residential buildings. This has a connection to the poor commitment by the leadership of organisations to consider the use of incentives as an option to facilitate the implantation of energy efficiency. This low leadership commitment can partly be attributed to the weak implementation framework of most government policies as well as poor accountability. This low leadership commitment is contrary to the situation in the UK where the government has criteria for investment appraisal to ensure regulating agencies have benchmarks to meet to obtain effective implementation of government policies on energy efficiency (Rosenow et al., 2018). Similarly, the collective regional efforts by EU on implementing the UN SDGs, which also aligns with achieving sustainable energy saving practice, also have some impact in influencing leadership commitment as outlined in the current EU efforts in implementing energy policies (Tromop et al., 2015). Hence, the behaviour of the leadership of organisations towards sustainable energy efficiency in residential buildings could be improved by a realistic implementation framework, attitudinal change and accountability. 
Another major challenge identified in energy-saving behaviour is a lack of sufficient information available to households and poor training of staff within both government and private organisations. While over $60 \%$ of the participants are of the view that consumers and householder owners lack the knowledge and information on the appropriate products or measures to take for efficient use of energy in households, less than $40 \%$ are neutral or have divergent views. For instance, Participants $F$ and $G$ corroborate views on issues of poor knowledge, lack of information, false or misinformation as barriers to achieving energy efficiency in residential buildings. From discussion with the stakeholders, it was noted that poor information on new energy efficient technology, products and methods is a major barrier. Due to a lack of sufficient information on more sustainable energy approaches, most households rely on the use of a power generating set as an alternative to mainstream energy supply with a monthly minimum approximate cost of US\$250 (Osae-Brown and Olurounbi, 2019). This cost has a significant impact and is unrealistic to sustain for households that rely on salaries of less than US\$200 per month. The literature has also shown that relevant information and guidance on available products would ease the implementation of sustainable energy policies and activities (Palm and Reindl, 2018). It was highlighted by Participants B and $D$ that a lack of critical skills or education on energy efficiency and insufficient awareness are also constraints, restricting households from achieving sustainable energy savings. These lack of critical skills and education also have direct implications on the cost of energy consumption in residential buildings as compared to when there is awareness of alternative and more cost-effective approaches. Additionally, poor training of staff in energy companies or government regulators to facilitate the implementation of energy efficient policies would prevent the attainment of the desired goals of achieving an energy efficiency and saving culture in residential buildings. It was also noted that the slow adoption of new innovative technology is a barrier to achieving sustainable energy efficient households. In the UK, for instance, the use of more innovative energy-efficient building materials for recent buildings is mandatory in line with government policies to achieve the UN SDGs (Department for Energy and Climate Change, 2012). However, this is not the case in Nigeria as the introduction of new products to facilitate energyefficient practice is uncoordinated and is on an individual or personal basis rather than by deliberate government efforts; this is a huge barrier to attaining energy efficiency in residential homes in Nigeria (as well as in achieving the UN SDGs).

During the data collection and interview sessions with the participants within the research, it was also identified that poor financial support has a significant impact on achieving sustainable energy-savings in residential buildings. In Nigeria, poor funding for energy-efficient projects and the non-availability of requisite resources to develop the required infrastructure are also key setbacks in this regard (amongst other financial challenges). This is made worse in the current financial situation, with Nigeria going into recession in 2020, the negative financial impact of COVID-19 and huge funds being channelled to address the present security challenges. It was also noted within the literature that the extreme fluctuation in the fuel price, which is the main source of revenue for Nigeria, also reduces the resources allocated to the energy sector (Geissler et al., 2018). all these reasons, amongst other reasons, were reiterated by the stakeholders, particularly by the government regulators in the energy sector, during the interview sessions. To assist in dealing with the situation, participants suggested that government subsidies for energy in Nigeria would reduce the cost paid by households. However, this approach is currently not sustainable because of the huge financial burden faced by the 
economy and a lack of funds to provide the requisite infrastructure for a more sustainable energy saving culture. Another major area of concern is the inadequate use of technology or energy efficient equipment, and poor standards of equipment and standardization processes. It was noted by the participants that the high cost of more reliable energy efficient equipment is also an impediment to achieving sustainable energy savings. Furthermore, some participants reflected on certain other barriers including a poor regulatory framework to ensure high quality equipment is imported into the country, the risk associated with new technology, and the absence of innovative technology within the country. Thus, the high cost could prevent low-income earners from purchasing more reliable energy efficient equipment, while poor standards and design could erode trust in such technology thereby instigating a barrier to attaining a more sustainable energy saving culture amongst residential households.

The discussions above highlight the obstacles to energy savings in residential buildings from the stakeholders' perspectives. The study elicited some major findings. One of the major findings of the research is the existential gap in top management commitment to ensure full implementation of existing policies or national strategies on the sustainable efficiency of households. This issue could have a direct effect on Nigeria's ability to meet some of its commitments to the UN SDGs. Additionally, poor knowledge of new sustainable energy saving products, misinformation, poor training and education, and a lack awareness are also huge impediments in this regard. Hence, a holistic framework on continuous awareness and on an extensive capacity building programme in sustainable energy savings' culture and equipment could make a significant impact in mitigating or reducing the future impact of such obstacles. Lastly, the research also revealed that government subsidies on renewable energy, government checks and the standardization of energy-efficient appliances imported into the country can improve the trust towards sustainable choices and promote efficient energy use. While this study highlights initial results obtained from research on energy efficiency in Nigeria, more data generation and analysis are required to make realistic conclusions on the subject matter.

\section{CONCLUSIONS}

The purpose of the current study was to determine different obstacles to, and pathways for, adopting energy efficiency and saving behaviour in Nigerian residential buildings. This study has identified several barriers to energy saving. The most significant findings to emerge from this study was that continuous awareness of energy-saving behavioural change, supportive leadership commitment and government subsidies on renewable energy crucial to achieving sustainable energy saving practice in Nigerian residential buildings. Furthermore, government checks and the standardization of energy-efficient appliances imported into the country can improve trust regarding sustainability and promote efficient energy use. Other results identified include information sharing and training, the use of technologies, financial support, and other organisational factors; these factors can facilitate energy efficiency policies' implementation and could also reduce the barriers affecting implementation. These findings complement those of earlier works in the field. Additionally, the outcome from this work is expected to further give a better understanding of energy use behaviour and to inform future energy policies and interventions relating to household energy saving.

The key contribution of this study has been to confirm the obstacles to energy saving in residential buildings. This will contribute to the existing knowledge on efficient energy 
consumption and on sustainable growth ambitions by providing a deeper insight from energy professionals. While the outcome of this exploratory research may offer the true state of a specific situation, but it may not be suitable for statistical generalisability. The broader impacts of energy efficiency and saving behaviour have not been assessed. As a result, the extent to which energy efficiency or energy-saving behaviour could enhance economic, environmental, and social sustainable goals is not well understood. As such, there will be a further survey examination to enable theory testing. The survey research will be undertaken to corroborate the findings of the interview analysis.

\section{ACKNOWLEDGEMENTS}

The authors would like to thank the organisers and editors of the World Construction Symposium, the interview respondents that provided their time and contributed their view and the funding body of this research (The Petroleum Technology Development Fund).

\section{REFERENCES}

Achtnicht, M., and Madlener, R., 2014. Factors influencing German house owners' preferences on energy retrofits. Energy Policy, 68, pp. 254-263.

Adeniyi, F., 2019. Overcoming the market constraints to on-grid renewable energy investments in Nigeria. The Oxford Institue for Energy Studies. [Online] Avaible from: https://www.oxfordenergy.org/wpcms/wp-content/uploads/2019/11/Overcoming-the-MarketConstraints-to-On-Grid-Renewable-Energy-Investments-in-Nigeria-EL37.pdf [Accesed 30 May 2021].

African Development Bank (AFDB), 2011. Private Sector Development as an engine of Africa's Economic Development. [Online]. Available from: https://www.afdb.org/sites/default/files/documents/publications/african_development_report_2011.pd f [Accesed : 03 March 2020].

Allouhi, Y., El Fouhi, A., Kousksou, T., Jamil, A., Zeraouli, Y. and Mourad., 2015. Energy consumption and efficiency in building: Current status and future trends. Journal of Cleaner Production, 109, pp. 118-130.

Babin, B., Quinlan, C., Carr, J., Griffin, M. and Zikmund, W., 2019. Business Research Method. $2^{\text {nd }}$ ed. China: Cengage learning.

Bertoldi, P., Hirl, B. and Labanca, N., 2012. Energy efficiency status report .Electricity consumption and efficiency trend in the EU-27, Luxembourg:Publications office of the European Union. [Online]. Available from: https://ec.europa.eu/jrc/sites/jrcsh/files/energy-efficiency-status-report-2012.pdf [Accessed 21 May 2020]

Braun, V., Clarke, V. and Weate, P., 2016. Using thematic analysis in sport and exercise research. In Handbook of Qualitative Research in sport and exercise in Smith, B and Sparkes, A, pp. 191-205. London: Routledge.

Braun, V. and Clarke, V., 2006. Using thematic analysis in psychology. Qualitative Research in Psychology, 3(2), pp. 77-101.

Burton, M., 2018. Justice on the line? A comparison of telephone and face-to face advice in social welfare legal aid. Journal of Social Welfare and Family Law, 40(2), pp. 195-215.

Caird, S., Roy, R. and Herring, H., 2008. Improving the energy performance of UK households: Results from surveys of consumer adoption and use of low-and zero-carbon technologies. Energy Efficiency, 1(2), p. 149.

Camarasa, C., Kalahasthi, L. and Rosado, 1., 2021. Drivers and barriers to energy-efficient technologies (EETs) in EU residential buildings. Energy and Built Environment, 2(3), pp. 290-301.

Dietz, T., Gardner, G.T., Gilligan, J., Stern, P.C. and Vandenbergh, M.P., 2009. Household actions can provide a behavioral wedge to rapidly reduce US carbon emissions. Proceedings of the National Academy of Sciences, 106(44), pp. 18452-18456.

Emodi, N.V. and Yusuf, S.D., 2015. Improving electricity access in Nigeria: Obstacles and the way forward. International Journal of Energy Economics and Policy, 5(1), pp. 335-351. 
Geels, F. W., Schwanen, T., Sorrell, S., Jenkins, K. and Sovacool, B. K., 2018. Reducing energy demand through low carbon innovation: A sociotechnical transitions perspective and thirteen research debates. Energy Research and Social Science, (40), p. 2.

Geissler, S., Österreicher, D. and Macharm, E. 2018. Transition towards energy efficiency: Developing the Nigerian building energy efficiency code. Sustainability, 10(8), pp. 1-21

Gillham, B., 2005. Research Interviewing: The range of techniques: A practical guide. United Kingdom: McGraw-Hill Education.

Hargreaves, T., Hielscher, S., Seyfang, G. and Smith, A., 2013. Grassroots innovations in community energy: The role of intermediaries in niche development. Global Environmental Change, 23(5), pp. 868-880.

Hart, E.W., Pounds, J., LaShell, C. and Graham, J., 2009. The leadership challenge in the energy sector. [Online] Available from: https://www.ccl.org/wp-content/uploads/2015/04/CCLEnergySector.pdf [Accessed 04 April 2021]

Ikpe, E. and Torriti, J., 2018. A means to an industrialisation end? Demand side management in Nigeria. Energy Policy, 115, pp. 207-215.

International Energy Agency, 2015. Shaping a secure and sustainable energy future for all. [Online] Available from :https://doi.org/https://www.iea.org/publications/ [Accessed 4 November 2018].

Janda, K.B., 2011. Buildings don't use energy, people do. Architectural Science Review, 54(1), pp. 15-22. https://doi.org/10.3763/asre.2009.0050

King, N., Horrocks, C. and Brooks, J., 2018. Interviews in qualitative research. SAGE Publications Ltd.

Li., Y., Zhu., N., and Qin., B., 2019. Major Barriers to the new residential building energy-efficiency promotion in China: Frontlines' perceptions. Energies, 12, p. 1073

National Energy Policy (NEP)., 2003. Energy Commission of Nigeria. Federal Republic of Nigeria. [Online] Available from:

http://rea.gov.ng/wp-content/uploads/2017/09/National_Energy_Policy_Nigeria.pdf. [Accessed 02 November 2019]

Olaniyan, K., McLellan, B., Ogata, S. and Tezuka, T., 2018. Estimating residential electricity consumption in Nigeria to support energy transitions. Sustainability, 10(5), p. 1440.

Ornaghi, C., Costanza, E., Kittley-Davies, J., Bourikas, L., Aragon, V. and James, P., 2018. The effect of behavioural interventions on energy conservation in naturally ventilated offices. Energy Economics, 74, pp. 582-591.

Osae-Brown, A. and Olurounbi, R., 2019. Nigeria runs on generators and nine hours of power a day. [Online] Available from: https:/www.bloomberg.com/news/articles/2019-09-23/nigeria-runs-ongenerators-and-nine-hours-of-power-a-day [23 Accessed July 2020].

Palm, J. and Reindl, K., 2018. Understanding barriers to energy-efficiency renovations of multifamily dwellings.2018. Energy Efficiency, 11(1), pp. 53-65.

Pelenur, M. and Cruickshank, H., 2012. Closing the energy efficiency gap: A study linking demographics with barriers to adopting energy efficiency measures in the home. Energy, 47(1), pp. 348-357.

Remy, T. and Chattopadhyay, D., 2021. Enhancing dispatch efficiency of the Nigerian power system: Assessment of benefits. Energy for Sustainable Development, 62, pp. 29-43.

Rosenow, J., Guertler, P., Sorrell, S. and Eyre, N., 2018.The remaining potential for energy savings in UK households. Energy Policy. 121. pp. 542-552.

Saunders, M., Philip, L. and Adrian., T., 2019. Research methods for business students. $8^{\text {th }}$ ed. Harlow: Pearson Education Limited

Sepúlveda, J., 2016a. Evaluation of research in the field of energy efficiency and MCA methods using publications databases. International Journal of Environmental, Chemical, Ecological, Geological and Geophysical Engineering, 10(2), pp. 219-222.

Sovacool, B.K., 2014. Diversity: Energy studies need social science. Nature News, 511(7511), p. 529.

Stern, P.C., Janda, K.B., Brown, M.A., Steg, L., Vine, E.L. and Lutzenhiser, L., 2016. Opportunities and insights for reducing fossil fuel consumption by households and organizations. Nature Energy, 1(5), pp. 1-6. 
Stieß, I, Dunkelberg, E., 2013. Objectives, barriers and occasions for energy efficient refurbishment by private homeowners. Journal of Cleaner Production, 48, pp. 250-59.

Tromop, R., Badaker, V., Dzioubinski, O., Foster, S., Held, S. Litvinyul, I. 2015. Best policy practices for promoting energy efficiency: A structured framework of best practices in policies to promote energy efficiency for climate change mitigation and sustainable development. UNECE Energy Series, 43.

Trotta, G., 2018. The determinants of energy efficient retrofit investments in the English residential sector. Energy Policy, 120, pp. 175-182.

Urban, F., Benders, R.M.J. and Moll, H.C., 2007. Modelling energy systems for developing countries. Energy Policy, 35(6), pp 3473-3482.

World Bank., 2019. World Development Indicators: Environment. [Online]. Available from https://datatopics.worldbank.org/world-development-indicators/ [Accessed: 15 May, 2021]. 